\title{
Phosphorus resource heterogeneity in microbial food webs
}

\author{
M. E. Muscarella ${ }^{1}$, K. C. Bird ${ }^{2}$, M. L. Larsen $^{1}$, S. A. Placella ${ }^{3}$, J. T. Lennon ${ }^{1, *}$ \\ ${ }^{1}$ Department of Biology, Indiana University, Bloomington, Indiana 47405, USA \\ ${ }^{2}$ Cary Institute of Ecosystem Studies, Millbrook, New York 12545, USA \\ ${ }^{3}$ Institut National de la Recherche Agronomique, Unité Mixte de Recherche Eco\&Sols, 34060 Montpellier, France
}

\begin{abstract}
Food webs are often regulated by the bottom-up effects of resource supply rate. However, heterogeneity within a resource pool may also affect the structure and function of communities. To test this hypothesis, we measured the responses of aquatic microbial food webs in experimental mesocosms to the addition of 4 different phosphorus (P) sources: orthophosphate $\left(\mathrm{PO}_{4}{ }^{3-}\right), 2$-aminoethylphosphonate (AEP), adenosine triphosphate (ATP), and phytic acid (PA). Based on 16S rRNA gene sequencing, we found that $\mathrm{P}$ resource heterogeneity altered community assembly for bacteria and eukaryotic algae, suggesting that these microbial functional groups may be comprised of P-specialists. In contrast, cyanobacteria were relatively unaffected by our treatments, suggesting that these microorganisms may adopt a more generalist strategy for Pacquisition. Furthermore, our results revealed that $\mathrm{P}$ resource heterogeneity affected food web and ecosystem attributes such as nutrient concentrations, bacterial productivity, algal biomass, and ecosystem respiration. Lastly, we found no evidence for non-additive effects of resource heterogeneity based on a treatment where a set of mesocosms received all 4 sources of P. Instead, our results support the view that there may be non-substitutable classes of $\mathrm{P}$ in aquatic ecosystems. Specifically, microbial food webs were more sensitive to P-containing biomolecules $\left(\mathrm{PO}_{4}{ }^{3-}\right.$ and ATP) than P-containing structural or storage molecules (AEP and PA). Our results demonstrate that not all P resources are the same; although historically overlooked, P resource heterogeneity may have important implications for understanding and predicting the structure and function of aquatic communities.
\end{abstract}

KEY WORDS: Specialist - Generalist - Biodiversity - Bacterial community composition . Metabolism $\cdot$ Ecosystem function $\cdot$ Algae $\cdot$ Eutrophication

\section{INTRODUCTION}

Resource limitation has strong bottom-up effects on the structure and function of ecosystems. It is well established that the concentration of growth-limiting resources can influence population abundances, species interactions, food web dynamics, and ecosystem productivity (Oksanen et al. 1981, Carpenter et al. 2001). However, variation within a given resource pool can also have profound effects on a range of ecological processes (Tylianakis et al. 2008, Kominoski et al. 2009). Resources exist in multiple forms, and many species have evolved the capacity to partition this heterogeneity (Schoener 1974, Finke \& Snyder 2008). For example, some terrestrial plants can meet their nitrogen demands through the uptake of ammonium, nitrate, and amino acids (McKane et al. 2002), while phytoplankton species absorb different wavelengths of the light spectrum to meet their photosynthetic needs (Stomp et al. 2004). Ultimately, resource heterogeneity provides an opportunity for ecological specialization, which has implications for competitive interactions and species coexistence (Wilson \& Yoshimura 1994). Few studies, however, 
have explored the degree to which resource heterogeneity affects the assembly and functioning of microbial communities.

Phosphorus $(\mathrm{P})$ is a limiting resource in many ecosystems, especially aquatic habitats (Elser et al. 2007). It is an essential element that is required for synthesizing ribosomes, DNA, and cell membranes. Similar to other resources, $\mathrm{P}$ exists in various forms. The most biologically available form of $\mathrm{P}$ is orthophosphate $\left(\mathrm{PO}_{4}{ }^{3-}\right)$. However, because it is in high demand, $\mathrm{PO}_{4}{ }^{3-}$ is only found at trace concentrations in most aquatic ecosystems (Hudson et al. 2000). Instead, most $\mathrm{P}$ is contained in organic molecules such as oxidized phosphate esters or reduced phosphonates (Turner et al. 2005, White \& Metcalf 2007). Some of these P-containing molecules are common cellular components, such as phospholipids, nucleic acids, and nucleosides, which have relatively rapid turnover rates (Løvdal et al. 2007). Other P-containing molecules in the environment are complex structural or storage compounds (e.g. teichoic acids, phytates, and phosphonates) that are more resistant to degradation (Ternan et al. 1998, Heath 2005).

Microorganisms vary in their ability to use different forms of $\mathrm{P}$. Most microbes can readily transport $\mathrm{PO}_{4}{ }^{3-}$ across their cell membranes. However, in response to long-term P-limitation, some microorganisms have evolved various P-acquisition strategies, which include: (1) induction of high affinity receptors to increase $\mathrm{PO}_{4}{ }^{3-}$ transport (Makino et al. 1989); (2) degradation of organic $\mathrm{P}$ esters via the production alkaline phosphatases, lipases, and nucleases (Lennon 2007, Luo et al. 2009); (3) luxury uptake and storage of $\mathrm{P}$ as polyphosphates (Orchard et al. 2010); and (4) cleavage of the C-P bonds found in phosphonates via hydrolases and lyases (Villarreal-Chiu et al. 2012). Based on genomic and metagenomic surveys, it appears that these alternative P-acquisition strategies are prevalent in aquatic ecosystems (Luo et al. 2009, Coleman \& Chisholm 2010). However, the distribution of these traits among microbial taxa is unresolved. In some cases, P-acquisition traits appear to have broad phylogenetic distributions (Newton et al. 2010). In other cases, the presence or absence of Prelated genes can vary within a single group of bacteria (Martiny et al. 2009). Given that P-limitation is common in aquatic habitats, it is possible that many microorganisms are generalists and possess a suite of P-acquisition strategies. If true, we might expect that aquatic microbial communities are insensitive to $\mathrm{P}$ resource heterogeneity. Alternatively, if P-acquisition genes are non-randomly distributed among specialized taxa or if P-acquisition strategies differentially affect community performance, then $\mathrm{P}$ resource heterogeneity may influence the diversity, assembly, and function of microbial communities.

In the present study, we explored the effects of P resource heterogeneity on microbial community assembly, food web attributes, and ecosystem processes. Despite the fact that aquatic ecosystems receive a diversity of P molecules (Cade-Menun 2005), most studies to date have restricted their focus to a single form of this resource, $\mathrm{PO}_{4}{ }^{3-}$. Using experimental mesocosms, we supplied replicate aquatic food webs with 4 distinct P-containing molecules: orthophosphate $\left(\mathrm{PO}_{4}{ }^{3-}\right)$, 2-aminoethylphosphonate (AEP), adenosine triphosphate (ATP), and phytic acid (PA). We tested the hypothesis that, owing to ecological specialization, distinct bacterial and algal communities would develop in response to different $\mathrm{P}$ sources. We also tested the hypothesis that $\mathrm{P}$ resource heterogeneity would affect food web structure (algal biomass and zooplankton abundance) and ecosystem processes (microbial and ecosystem metabolism). To address these hypotheses, we used a multiple model selection approach to compare a priori groupings of the different $P$ resources. Lastly, facilitation or interference among substitutable resources can have non-additive effects on ecological processes (Tilman 1980). We tested this hypothesis by quantifying community and functional responses to a mixture of multiple P sources.

\section{MATERIALS AND METHODS}

\section{Experimental design}

Mesocosm experiment. To test how $\mathrm{P}$ resource heterogeneity affects planktonic ecosystems, we set up a one-factor, randomized mesocosm study at the Michigan State University W. K. Kellogg Biological Station Experimental Pond Facility in Hickory Corners, Michigan, USA. We filled 24 mesocosms (300 l cattle tanks) with ground water from a nearby well on 14 July 2011. After a 1 wk equilibration period, we inoculated each mesocosm with a mixture of bacteria, phytoplankton, and zooplankton from 2 nearby lakes: eutrophic Wintergreen Lake and oligotrophic Little Long Lake. We then randomly assigned replicate mesocosms $(n=4)$ to 1 of 6 treatments. One set of mesocosms received no added $\mathrm{P}$ and served as a control. The second set of mesocosms received one of the following $\mathrm{P}$ sources: orthophosphate $\left(\mathrm{PO}_{4}{ }^{3-}\right.$, added as $\mathrm{KH}_{2} \mathrm{PO}_{4}$ ), 2-aminoethylphosphonate (AEP), adenosine triphosphate (ATP), or phytic acid (PA). Lastly, to test for non-additive effects of $\mathrm{P}$ resource 
heterogeneity, we created a mixture treatment that consisted of equal molar ratios of each $\mathrm{P}$ source (i.e. $\mathrm{PO}_{4}{ }^{3-}, \mathrm{AEP}, \mathrm{ATP}$, and $\left.\mathrm{PA}\right)$. We selected these $\mathrm{P}$ sources based on a previous study, which documented divergent patterns in $\mathrm{P}$ use by different groups of freshwater bacteria (Bird 2012). In addition, the P sources used in the present study capture a gradient in structural complexity (as determined by Bertz chemical complexity) and energy content (as determined by Gibbs free energy of formation, $\Delta_{\mathrm{f}} \mathrm{G}$ ) (Fig. 1, Table 1). With the exception of the controls, we added enough $\mathrm{P}$ at the beginning of the experiment (Day 0) to raise the total P (TP) concentration in

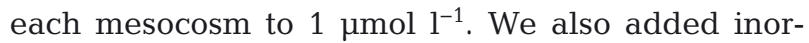
ganic nitrogen (N) as an equal molar mix of $\mathrm{NaNO}_{3}$ and $\mathrm{NH}_{4} \mathrm{Cl}$ to achieve a target $\mathrm{N}: \mathrm{P}$ molar ratio of approximately 40:1. Following these initial additions, we added $\mathrm{N}$ and $\mathrm{P}$ every other day assuming a $5 \%$ loss $\mathrm{d}^{-1}$ (Lennon et al. 2003).

Sampling. We sampled the mesocosms twice during the experiment. The first sampling occurred on Day 11 and was intended to capture the initial responses of faster growing microorganisms. The second sampling was conducted on Day 28, and was<smiles>O=P([O-])([O-])[O-]</smiles>

Orthophosphate $\left(\mathrm{PO}_{4}{ }^{3-}\right)$

\section{2- Aminoethylphosphonate (AEP)}

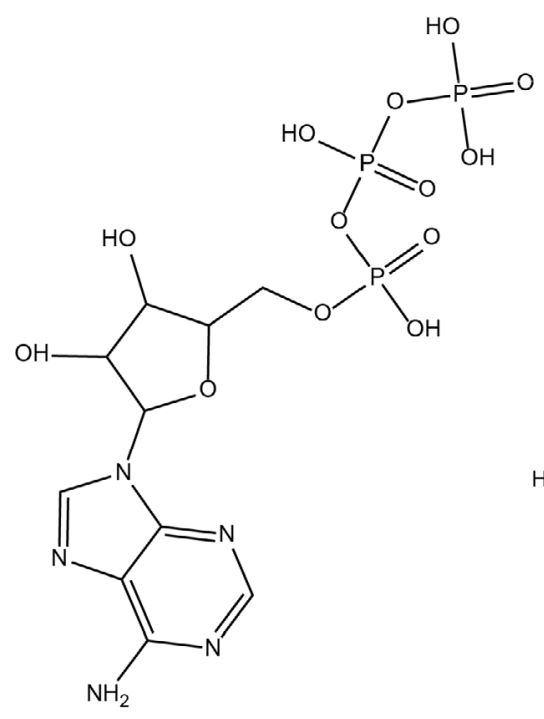

Adenosine Triphosphate (ATP)

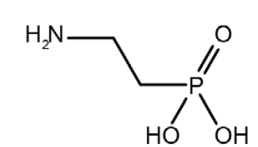

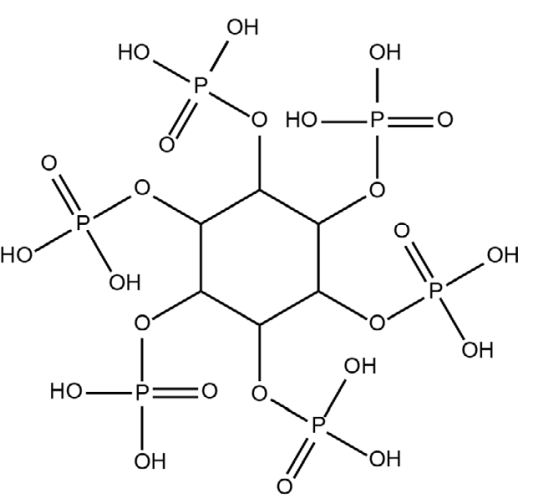

Phytic Acid (PA)
Fig. 1. Chemical structures of the phosphorus $(\mathrm{P})$ resources used in our experimental mesocosm study. See Table 1 for additional information
Table 1. Chemical complexity of different phosphorus (P) sources used in the experimental mesocosm study. Bertz complexity was calculated according to Bertz (1983) using the R package ' $\mathrm{QuACN}$ '. Gibbs free energy of formation values were obtained from http://metacyc.org

\begin{tabular}{|lcc|}
\hline Molecule & $\begin{array}{c}\text { Bertz } \\
\text { complexity }\end{array}$ & $\begin{array}{c}\text { Gibbs free energy } \\
\left(\mathrm{K}_{\mathrm{cal}} \mathrm{mol}^{-1}\right)\end{array}$ \\
\hline Orthophosphate $\left(\mathrm{PO}_{4}{ }^{3-}\right)$ & 15.2 & -261.97 \\
2-aminoethylphosphonate (AEP) & 271.0 & -211.01 \\
Adenosine triphosphate (ATP) & 514.1 & -671.96 \\
Phytic acid (PA) & 457.9 & -1494.96 \\
\hline
\end{tabular}

used to assess the response of slower growing zooplankton, as well as ecosystem processes. Samples were obtained with a $1 \mathrm{~m}$ depth-integrated sampler at the center of each mesocosm, transferred into 11 acid washed bottles, and stored on ice while being transported to the laboratory for processing.

Nutrient chemistry. We measured the concentrations of TP, total nitrogen (TN), and dissolved organic carbon (DOC) in each mesocosm sample. TP was measured on unfiltered samples spectrophotometrically using the ammonium molybdate method following oxidation by persulfate digestion (Wetzel \& Likens 2000). TN $\left(\mathrm{NO}_{\mathrm{x}}+\mathrm{NH}_{4}\right)$ was measured on unfiltered water samples using an Alpkem Model 3550 Flow Analyzer with cadmium coil (OI Analytical) following oxidation by persulfate digestion. DOC was measured by oxidation and non-dispersive infrared detection on $0.7 \mu \mathrm{m}$-filtered (Whatman, GF/F) samples using a Shimadzu TOC-V carbon analyzer.

\section{Microbial composition}

Community sequencing. We tested for the effect of $\mathrm{P}$ resource heterogeneity on the composition and diversity of aquatic microorganisms using 16S rRNA gene sequencing. We collected planktonic biomass on $47 \mathrm{~mm}$ $0.2 \mu \mathrm{m}$ Supor Filters (Pall) using vacuum filtration. We extracted DNA from the filters using the FastDNA Spin Kit (MP Biomedicals) and cleaned the extracts via ethanol precipitation. We amplified the 16S rRNA genes using barcoded primers designed for the 
Illumina MiSeq sequencing platform (Caporaso et al. 2012). Amplicons were sequenced using $250 \times 250$ paired-end sequencing on an Illumina MiSeq at the Indiana University Center for Genomics and Bioinformatics. Paired-end raw 16S rRNA sequences reads were assembled into contigs using the Needleman algorithm (Needleman \& Wunsch 1970). After quality trimming with a moving average quality score (window $50 \mathrm{bp}$, minimum quality score 35), we aligned our sequences to the Silva Database v. 102 (Yilmaz et al. 2014) using the Needleman algorithm. Finally, chimeric sequences were detected and removed using the UCHIME algorithm (Edgar et al. 2011). All initial sequence processing was completed using the software package mothur v. 1.31.2 (Schloss et al. 2009).

Functional groups. We separated sequences into 3 functional groups based on 16S rRNA sequence identity: bacteria (non-cyanobacterial), cyanobacteria, and eukaryotic algae (classified via choloroplasts, see Eiler et al. 2013). We determined 16S rRNA sequence identity using the Ribosomal Database Project's 16S rRNA reference sequences and taxonomy version 7 (Cole et al. 2009). Unwanted sequences such as mitochondria, archaea, and other unclassifiable sequences were removed. We then clustered sequences for each group into operational taxonomic units (OTUs) using average neighbor linkage distance and $97 \%$ sequence similarity. All sequence classification and clustering was completed using the software package mothur.

Diversity estimation. We estimated taxon richness and taxon evenness in each mesocosm for the 3 microbial functional groups. For richness, we used a resampling approach that subsampled an equal number of sequence observations per mesocosm. We calculated richness by summing the number of taxa (OTUs) represented. We subsampled to 10000 observations for bacteria and cyanobacteria and to 100 observations for eukaryotic algae. We then resampled 999 additional times and calculated the average richness estimates $( \pm \mathrm{SE})$ for each mesocosm. Second, using the same resampling approach, we estimated taxa evenness using Pielou's evenness (Pielou 1969). All of the diversity estimations were performed in the R statistical environment v. 3.0.2 (R Core Development Team 2012).

\section{Food web and ecosystem responses}

Bacterial metabolism. We assessed the metabolic responses of bacteria by measuring bacterial produc- tivity (BP), bacterial respiration (BR), and bacterial growth efficiency (BGE). We estimated $\mathrm{BP}$ as the uptake and incorporation of ${ }^{3} \mathrm{H}$-leucine $\left(50 \mathrm{nmol} \mathrm{l}^{-1}\right.$ final concentration) into bacterial protein using the microcentrifuge method (Smith \& Azam 1992). BR was estimated based upon the rate of dissolved oxygen depletion on $2.7 \mu \mathrm{m}$-filtered (Whatman GF/D) samples using an automated optical $\mathrm{O}_{2}$ system (PreSens SensorDish; Briand et al. 2004). From this information, we estimated BGE as BP/(BP + BR).

Algal biomass and zooplankton abundance. We measured algal biomass and zooplankton abundance to assess food web responses to the P treatments. We estimated algal biomass as the concentration of chlorophyll a measured by cold ethanol extraction of $0.7 \mu \mathrm{m}$-filtered (Whatman GF/F) samples using a Turner Biosystems Fluorometer. We sampled zooplankton from each mesocosm using a SchindlerPatalas trap (80 $\mathrm{\mu m}$ net). After preserving the samples in $70 \%$ ethanol, we estimated the abundance of cladocerans and copepods by direct counts with a dissecting microscope. We grouped zooplankton into these categories because cladocerans and copepods have different top-down effects on microbial functional groups (Sommer \& Sommer 2006) and because they have different P requirements (Sterner \& Elser 2002).

Ecosystem processes. We estimated changes in ecosystem respiration ( $\mathrm{R}$ ) among $\mathrm{P}$ treatments using a 2-point estimation of oxygen demand from dusk to dawn (Odum 1956). In addition, we measured net primary productivity (NPP) based on the difference in gross primary productivity (2-point estimate of oxygen accumulation during daylight) and $\mathrm{R}$, assuming constant rates throughout the day (Odum 1956).

\section{Statistical analyses}

Microbial compositional responses. To visualize compositional responses to our treatments, we used Principal Coordinates Analysis (PCoA) on Bray-Curtis distance matrices of log-transformed relative OTU abundance data (Anderson et al. 2006). Then, to test hypothesized differences in microbial composition between $\mathrm{P}$ treatments, we used PERMANOVA (Anderson 2001) implemented with the adonis function in the R package 'vegan' v. 2.0-9 (Oksanen et al. 2013). In cases where we found significant differences between treatments, we used indicator species analysis to determine which OTUs contributed to the community response. All calculations were done in the R statistical environment. 
Table 2. Phosphorus (P) resource substitutability models. We used a multiple model comparison approach to determine whether univariate and multivariate response variables were best supported by the $\mathrm{P}$ additions to experimental mesocosms. P sources: orthophosphate $\left(\mathrm{PO}_{4}{ }^{3-}\right), 2$-aminoethylphosphonate (AEP), adenosine triphosphate (ATP), phytic acid (PA)

\begin{tabular}{|lll|}
\hline Model & Grouping & Rationale \\
\hline Inorganic & $\mathrm{PO}_{4}{ }^{3-} \neq \mathrm{AEP}=\mathrm{ATP}=\mathrm{PA}$ & $\mathrm{PO}_{4}{ }^{3-}$ is the P source most readily moved across cell membranes \\
Biomolecule & $\mathrm{PO}_{4}{ }^{3-}=\mathrm{ATP} \neq \mathrm{AEP}=\mathrm{PA}$ & $\mathrm{PO}_{4}{ }^{3-}$ and ATP are common in biological reactions across all taxa \\
Complexity & $\mathrm{PO}_{4}{ }^{3-} \neq \mathrm{AEP} \neq \mathrm{ATP} \neq \mathrm{PA}$ & Complex molecules require more energy to transport and metabolize \\
\hline
\end{tabular}

Nutrient, food web, and ecosystem responses. To test our hypotheses about nutrient, food web, and ecosystem responses, we used ANOVA, model selection, and deviance tests. First, to test for P-limitation in our experimental system, we used ANOVA to compare treatments and controls for each response variable. Second, to test the hypothesis that $\mathrm{P}$ resource heterogeneity influences planktonic community structure and function, we used a model selection approach to compare responses in each $\mathrm{P}$ treatment based on 3 resource substitutability models: Inorganic, Biomolecule, and Complexity (Table 2). The Inorganic model predicted that planktonic responses would be determined by whether or not added $\mathrm{P}$ resource was in an inorganic or organic form. The Biomolecule model predicted that planktonic responses would be determined by whether or not the added $\mathrm{P}$ resource was a biomolecule versus non-biomolecule. The Complexity model predicted that planktonic responses would be determined by complexity of the $\mathrm{P}$ resource as determined by Gibbs free energy of formation (results from Bertz Complexity were similar). We used an information criterion metric (Akaike information criterion, AIC) to assess model fit for univariate responses related to diversity (richness and evenness), bacterial metabolism (BP, BR, and BGE), food web responses (algal biomass and zooplankton abundance), and ecosystem processes (NPP and R). Likewise, to determine which model best supported the observed variation in multivariate community composition data, we compared PERMANOVA results $\left(\mathrm{R}^{2}\right)$ for each treatment according to our resource substitutability models. Finally, we tested for non-additive effects in the mixture treatments. For univariate response variables, we used a deviance model (Loreau 1998) to test for non-additive effects of the mixture treatment. This approach identified differences in observed responses in the mixture treatment versus expected responses, based on group means, assuming equal and independent influences of each $\mathrm{P}$ resource. We used a $t$-test to determine if deviances were significantly different from zero. For multivariate data, we tested for non-additivity by comparing community composition in mixture and single source treatments using PERMANOVA.

\section{RESULTS}

\section{Nutrient chemistry}

Our experimental P manipulations had strong effects on mesocosm nutrient chemistry. As expected, $\mathrm{P}$ additions elevated TP concentrations across all treatments similarly (Fig. $2 \mathrm{~A}_{i} F_{1,22}=12.2, \mathrm{p}=0.002$ ). TN decreased in all treatments receiving $\mathrm{P}$ (Fig. 2B; $F_{1,22}=85.5, \mathrm{p}<0.001$ ), but the magnitude of this reduction was dependent on $\mathrm{P}$ source. Specifically, mesocosms receiving PA had $44 \%$ higher TN than mesocosms receiving other $\mathrm{P}$ sources, but these results did not lend support to any of the resource substitutability models relative to the null model where all $\mathrm{P}$ resources are different (Table 3). DOC was not significantly affected by the $\mathrm{P}$ treatments (Fig. 2C, $F_{1,22}=6.34, \mathrm{p}=0.23$ ). However, relative to the controls, DOC was $70 \%$ higher in mesocosms receiving $\mathrm{PO}_{4}{ }^{3-}$. In contrast, other treatments had no effect on DOC. Together, these results were best supported by the inorganic resource substitutability model (Table 3). Lastly, based on our deviance test, we found no evidence for a non-additive effect of the mixture treatment on $\mathrm{TP}, \mathrm{TN}$, or DOC $(\mathrm{p}>0.10)$.

\section{Microbial composition}

\section{Bacteria}

Despite having no effect on richness or evenness (Fig. 3), P treatments significantly affected bacterial community assembly. Based on PCoA, P treatments separated along the first PCoA axis, which explained $14.6 \%$ of the variation in community composition (Fig. 4). PERMANOVA results confirmed the significance of the ordination trend $\left(\mathrm{R}^{2}=0.34, \mathrm{p}<0.001\right)$ 


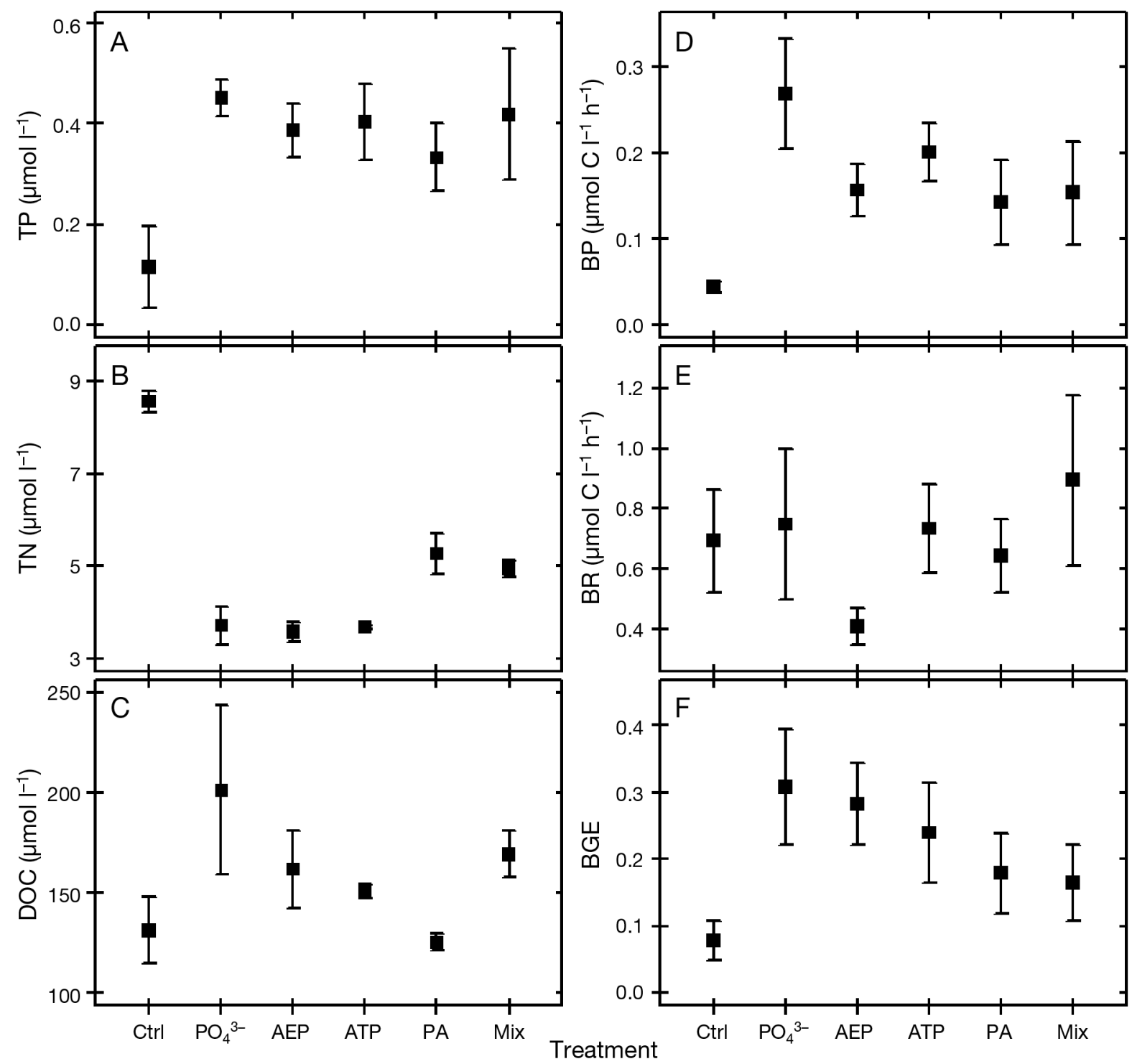

Fig. 2. Chemical and microbial responses (mean $\pm \mathrm{SE}$ ) in each phosphorus (P) treatment. All responses were measured on Day 11. (A) Total P (TP), (B) total nitrogen (TN), (C) dissolved organic carbon (DOC), (D) bacterial productivity (BP), (E) bacterial respiration (BR), and (F) bacterial growth efficiency (BGE). P treatments: orthophosphate $\left(\mathrm{PO}_{4}{ }^{3-}\right)$, 2 -aminoethylphosphonate (AEP), adenosine triphosphate (ATP), phytic acid (PA), an equal molar ratio of each P source (Mix), and a control without any additional $\mathrm{P}(\mathrm{Ctrl})$

and supported the biomolecule resource substitutability model (Table $4 ; \mathrm{R}^{2}=0.17 \mathrm{p}=0.001$ ). Results from the indicator species analysis suggest that $35 \%$ of bacterial sequences belonged to taxa that were associated with a particular $\mathrm{P}$ source and that $\mathrm{a}$ diverse collection of taxa, $70 \%$ of which were members of the Alphaproteobacteria and Betaproteobacteria, were responsible for the compositional pattern. Lastly, we found no evidence for a non-additive effect of the mixture treatment on bacterial community composition (PERMANOVA, $\mathrm{R}^{2}=0.05, \mathrm{p}=0.47$ ) or richness $(\mathrm{p}=0.10)$.

\section{Cyanobacteria}

$\mathrm{P}$ resource heterogeneity had a weak effect on cyanobacterial community composition. There was no obvious separation of communities based on P treatments along the primary or secondary PCoA axes (Fig. 4). This observation is consistent with the nonsignificant effect of $\mathrm{P}$ resource heterogeneity in our PERMANOVA model $\left(\mathrm{R}^{2}=0.26, \mathrm{p}=0.16\right)$. Additionally, $\mathrm{P}$ treatments had no effect on taxon richness (Fig. 3), but evenness in mesocosms receiving AEP was 30 to $50 \%$ lower than other treatments (Fig. 3; 
Table 3. Resource substitutability model selection for univariate responses to phosphorus (P) manipulations. Model selection was done by comparing Akaike information criterion (AIC) values of linear models grouping P treatments to the value of a null model comparing each treatment separately. Comparisons were done only in cases where the null model (treatment) was significant (indicating that at least one treatment was different). Values are $\triangle \mathrm{AIC}$, i.e. differences in AIC values between the null model and resource substitutability model. Negative values represent models that better fit the data than the null. $\triangle$ AIC values $<2$ (in bold) are the best representation of the data (Burnham \& Anderson 2004). 'Chemistry': total phosphorus (TP), total nitrogen (TN), and dissolved organic carbon (DOC); 'Bacterial': bacterial productivity (BP), bacterial respiration (BR), and bacterial growth efficiency (BGE); 'Ecosystem': chlorophyll a (Chl a), cladoceran:copepod ratio (Clad:Cope), ecosystem respiration (R), and net primary productivity (NPP). ns = not significant. AIC values are not reported for non significant models (-)

\begin{tabular}{|c|c|c|c|c|c|}
\hline & Response & $\mathrm{p}$ & $\begin{array}{c}\text { Inorganic } \\
\text { model }\end{array}$ & $\begin{array}{c}\text { Biomolecule } \\
\text { model }\end{array}$ & $\begin{array}{c}\text { Complexity } \\
\text { model }\end{array}$ \\
\hline Chemistry & $\begin{array}{c}\text { TP } \\
\text { TN } \\
\text { DOC }\end{array}$ & $\begin{array}{r}<0.001 \\
0.002 \\
<0.001\end{array}$ & $\begin{array}{l}\mathbf{- 3 . 1 2} \\
12.26 \\
\mathbf{- 2 . 2 1}\end{array}$ & $\begin{array}{r}\mathbf{- 3 . 1 8} \\
9.81 \\
0.63\end{array}$ & $\begin{array}{r}8.30 \\
45.73 \\
0.74\end{array}$ \\
\hline Bacterial & $\begin{array}{c}\text { BP } \\
\text { BR } \\
\text { BGE }\end{array}$ & $\begin{array}{c}0.01 \\
\mathrm{~ns} \\
0.04\end{array}$ & $\begin{array}{l}-2.65 \\
- \\
-2.37\end{array}$ & $\begin{array}{c}-2.21 \\
- \\
-1.72\end{array}$ & $\begin{array}{c}8.18 \\
- \\
2.46\end{array}$ \\
\hline Ecosystem & $\begin{array}{c}\text { Chl a } \\
\text { Clad:Cope } \\
\text { R } \\
\text { NPP }\end{array}$ & $\begin{array}{c}<0.001 \\
0.04 \\
0.01 \\
\text { ns }\end{array}$ & $\begin{array}{r}-3.49 \\
0.09 \\
-2.08 \\
-\end{array}$ & $\begin{array}{r}0.54 \\
-3.85 \\
-1.54 \\
-\end{array}$ & $\begin{array}{r}2.23 \\
-0.02 \\
-1.96 \\
-\end{array}$ \\
\hline
\end{tabular}

$\left.F_{3,12}=8.96, \mathrm{p}=0.002\right)$. Lastly, we found no evidence for a non-additive effect of the mixture treatment on cyanobacterial community composition (PERMANOVA, $\mathrm{R}^{2}=0.05$, $p=0.39)$ or richness $(p=0.45)$.

\section{Eukaryotic algae}

Despite lower sequence coverage relative to bacteria, we were able to detect that algae were relatively sensitive to the $\mathrm{P}$ treatments in our experiment. PCoA revealed strong separation of $\mathrm{P}$ treatments along the primary axis, which explained $34.5 \%$ of the variation in composition (Fig. 4). PERMANOVA results confirmed the significance of the ordination trend $\left(\mathrm{R}^{2}=0.47, \mathrm{p}<0.001\right)$ and supported the biomolecule resource substitutability model (Table $4 ; \mathrm{R}^{2}=0.18 \mathrm{p}=$ 0.01 ). Results from the indicator species analysis suggest that $87 \%$ of algal
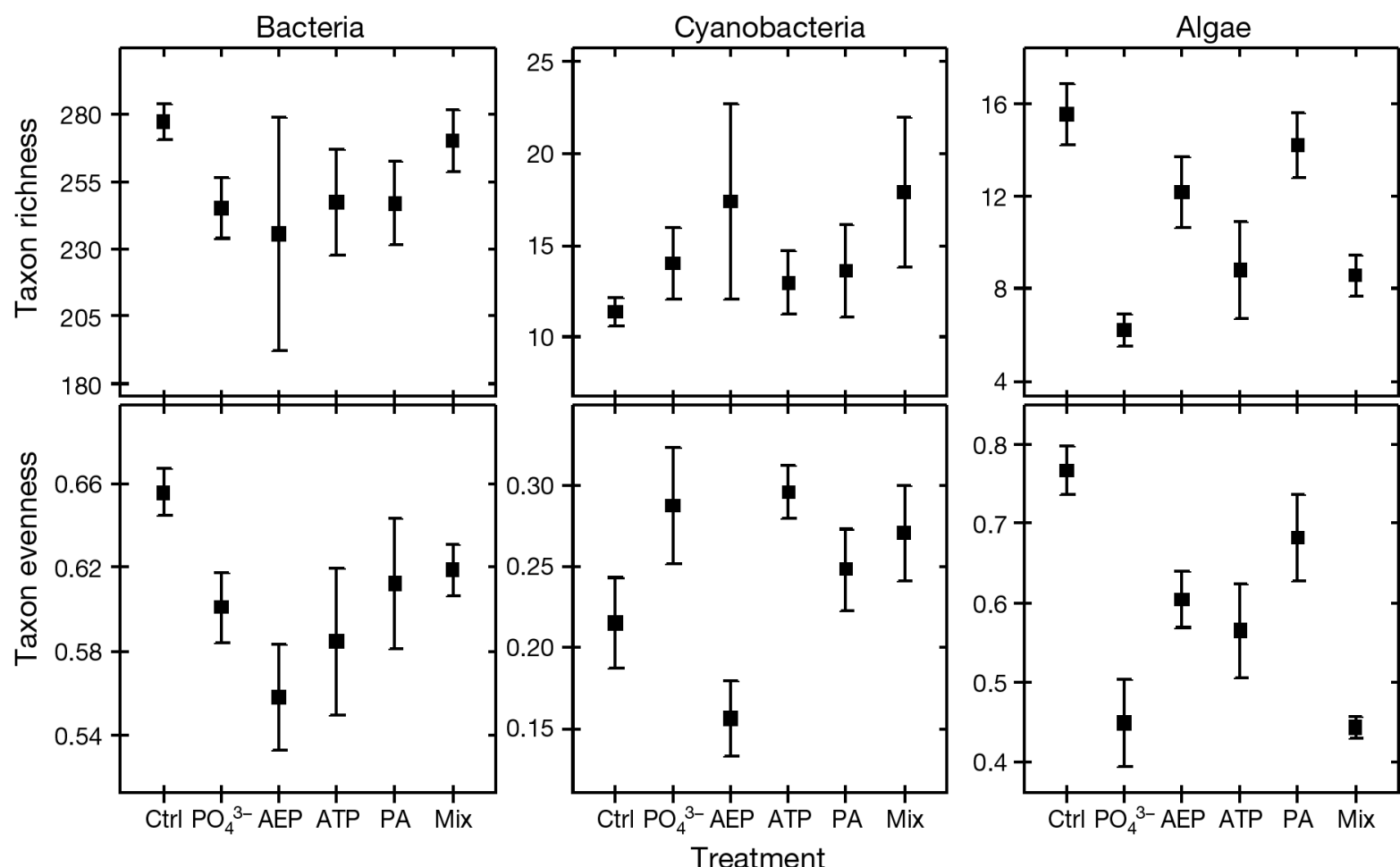

Fig. 3. Community diversity (richness and evenness) estimates (mean $\pm \mathrm{SE}$ ) for microbial functional groups in each phosphorus (P) treatment. Richness was estimated as total observed taxa in each mesocosm. Evenness was calculated using Pielou's Evenness. Phosphorus treatments: orthophosphate $\left(\mathrm{PO}_{4}{ }^{3-}\right), 2$-aminoethylphosphonate (AEP), adenosine triphosphate (ATP), phytic acid (PA), an equal molar ratio of each $\mathrm{P}$ source (Mix), and a control without any additional $\mathrm{P}$ (Ctrl) 

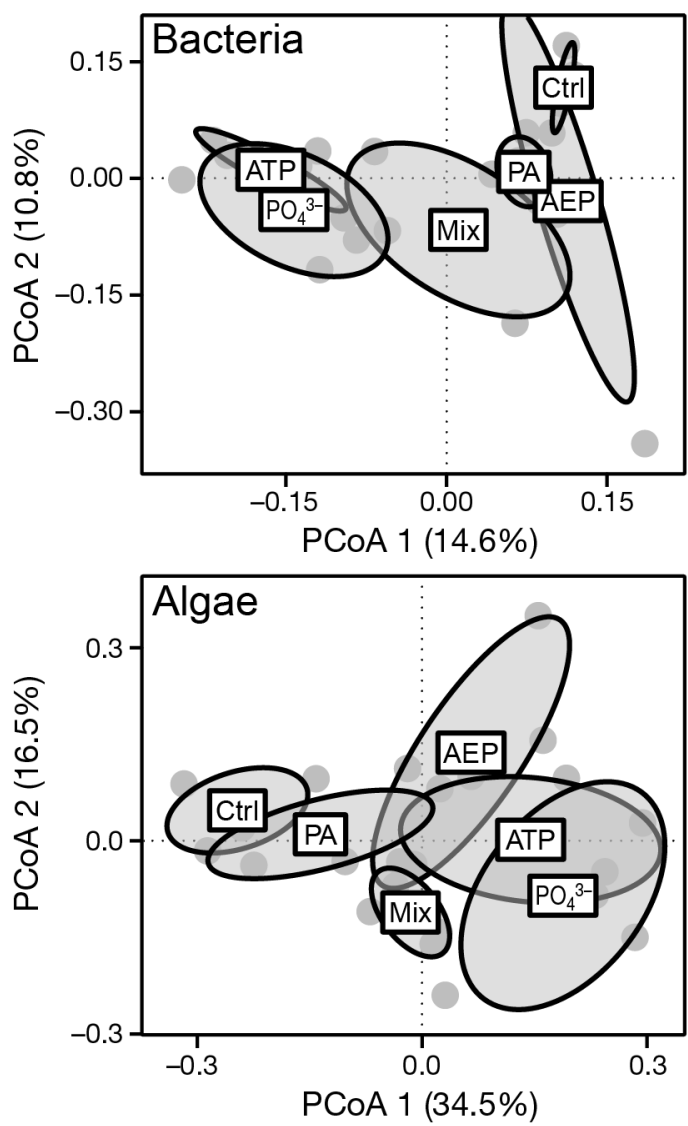

sequences belonged to taxa that were associated with a particular $\mathrm{P}$ source and that the majority (94\%) of these taxa belonged to the Bacilloriophyta (diatoms) and Chlorophyta. We also found significant differences in taxon richness (Fig. $3 ; F_{5,18}=7.72, \mathrm{p}<$ 0.001 ) and evenness (Fig. $3 ; F_{5,18}=8.34, \mathrm{p}<0.001$ ). Specifically, richness and evenness declined by 45 to $65 \%$ in mesocosms receiving $\mathrm{P}$ in the form of biomolecules $\left(\mathrm{PO}_{4}{ }^{3-}\right.$ and ATP), but only by 12 to $25 \%$ in mesocosms receiving other $\mathrm{P}$ sources. Lastly, we found no evidence for a non-additive effect of the mixture treatment on algal community composition (PERMANOVA, $\left.\mathrm{R}^{2}=0.09, \mathrm{p}=0.07\right)$ or richness $(\mathrm{p}=$ $0.17)$.

\section{Food web and ecosystem responses}

\section{Bacterial metabolism}

The P manipulations had strong effects on bacterial metabolism. BP increased to the same level in all $\mathrm{P}$ treatments relative to the control (Fig. 2D; $F_{1,22}=$ $7.58, p=0.01)$. Even though there were no significant

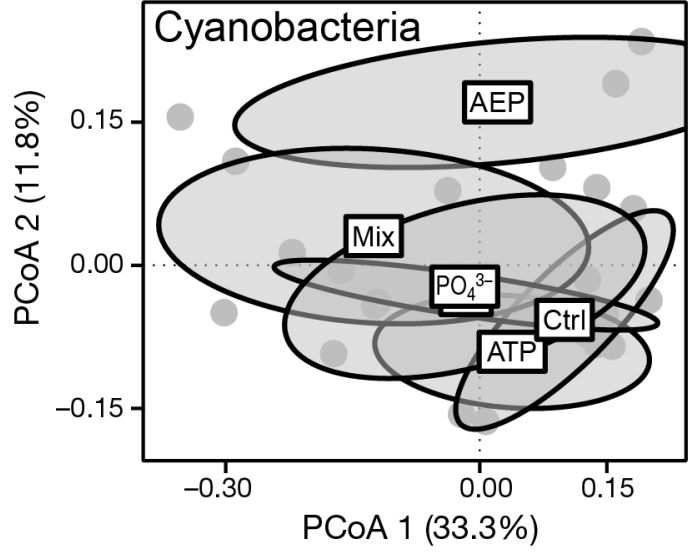

Fig. 4. Multivariate ordinations for 3 microbial functional groups based on principal coordinate analysis (PCoA). Ellipses represent weighted SE associated with treatments and were calculated using the ordiellipse function in the R package 'vegan'. Phosphorus (P) treatments: orthophosphate $\left(\mathrm{PO}_{4}{ }^{3-}\right)$, 2-aminoethylphosphonate (AEP), adenosine triphosphate (ATP), phytic acid (PA), an equal molar ratio of each P source (Mix), and a control without any additional $\mathrm{P}(\mathrm{Ctrl})$

Table 4. Resource substitutability model selection for multivariate community composition. Model selection was done by comparing permutation multivariate ANOVA (PERMANOVA) models for communities grouped according to our resource substitutability models (see Table 2). Comparisons were done only in cases where the overall treatment PERMANOVA was significant. Values are $\mathrm{R}^{2}$ for PERMANOVA under each resource substitutability model. The model(s) that best explained variation in community composition for each functional group are in bold; $\mathrm{ns}=$ not significant -: indicates that comparisons were not made owing to lack of statistical significance for the PERMANOVA model

\begin{tabular}{|lccccc|}
\hline Community & $\mathrm{p}$ & $\begin{array}{c}\text { Inorganic } \\
\text { model }\end{array}$ & $\begin{array}{c}\text { Biomolecule } \\
\text { model }\end{array}$ & $\begin{array}{c}\text { Complexity } \\
\text { model }\end{array}$ \\
\hline Bacteria & $<0.001$ & $0.09^{\mathrm{ns}}$ & $\mathbf{0 . 1 7}$ & $0.08^{\mathrm{ns}}$ \\
Cyanobacteria & $\mathrm{ns}$ & - & - & - \\
Algae & $<0.001$ & $0.13^{\mathrm{ns}}$ & $\mathbf{0 . 1 8}$ & $0.17^{\mathrm{ns}}$ \\
\hline
\end{tabular}

differences among $\mathrm{P}$ treatments, the variation in $\mathrm{BP}$ best supported the biomolecule resource substitutability model (Table 3). In contrast, BR was relatively constant across all treatments, suggesting that this metabolic process was not P-limited (Fig. 2E; $\left.F_{1,22}=0.74, \mathrm{p}=0.97\right)$. BGE increased in all $\mathrm{P}$ treat- 

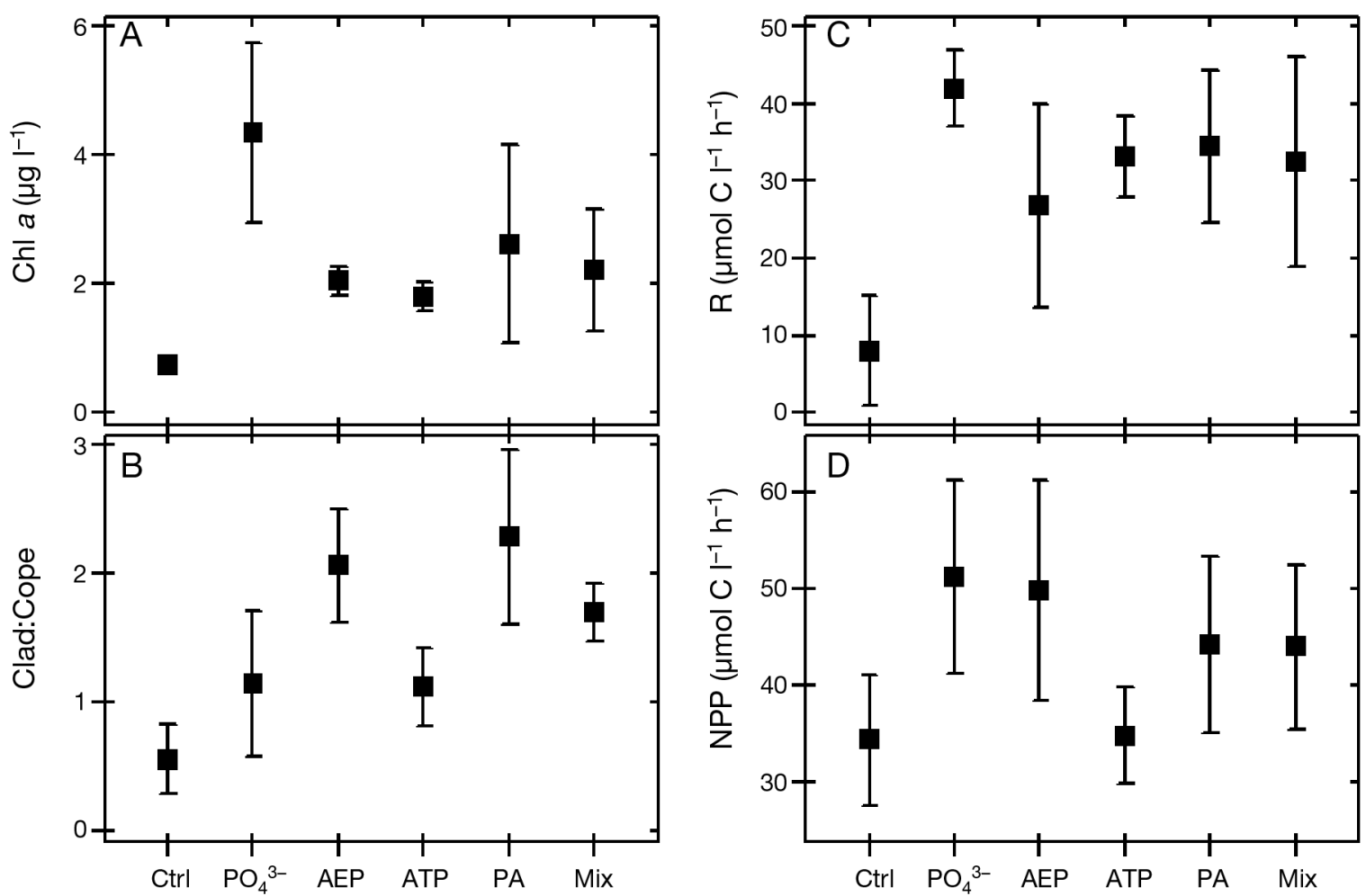

Fig. 5. Food web and ecosystem responses (mean $\pm \mathrm{SE}$ ) in each phosphorus (P) treatment. (A) Chlorophyll a (Chl a) as an estimate of algal biomass, (B) cladoceran:copepod ratio (Clad:Cope) as a measure of zooplankton community composition, (C) ecosystem respiration (R), and (D) net primary productivity (NPP). P treatments: orthophosphate $\left(\mathrm{PO}_{4}{ }^{3-}\right)$, 2-aminoethylphosphonate (AEP), adenosine triphosphate (ATP), phytic acid (PA), an equal molar ratio of each P source (Mix), and a control without any additional P (Ctrl)

ments relative to the control (Fig. $2 \mathrm{~F}_{;} F_{1,22}=5.01, \mathrm{p}=$ 0.04 ) and was best supported by the inorganic resource substitutability model (Table 3 ). Lastly, based on our deviance test, there was no evidence for a non-additive effect of the mixture treatment on $\mathrm{BP}$, $B R$, or BGE $(p>0.20)$.

Algal biomass and zooplankton abundance

Phytoplankton biomass (chlorophyll a) increased to the same level in all treatments compared to the control (Fig. 5A; assuming unequal variance, $F_{1,20}=16.0$, $\mathrm{p}<0.001$ ). Regardless, responses of phytoplankton biomass best supported the inorganic resource substitutability model (Table 3 ). In contrast, total zooplankton abundance was not affected by $\mathrm{P}$ treatments $\left(F_{1,22}=1.19, \mathrm{p}=0.29\right)$. However, we did find an approximately 2 -fold increase in the cladoceran: copepod ratio in all treatments relative to the control (Fig. 5B; $F_{1,22}=4.79, p=0.04$ ). In addition, some treatments (AEP and PA) had a higher average cladoceran:copepod ratio than the other treatments, which best supported the biomolecule resource substitutability model (Table 3). Lastly, based on our deviance tests for both phytoplankton biomass and zooplankton abundance, we found no evidence for a non-additive effect of the mixture treatment $(p>0.50)$.

\section{Ecosystem processes}

The $\mathrm{P}$ treatments had a significant effect on ecosystem processes in the mesocosms. $\mathrm{P}$ additions increased ecosystem respiration $(\mathrm{R})$ in all treatments compared to the control (Fig. $5 C_{i} F_{1,22}=6.79, p=$ 0.01 ), but variation in $\mathrm{R}$ supported both the inorganic and biomolecules resource substitutability models equally well (Table 3 ). Though there were increases in $\mathrm{R}$ in all treatments, $\mathrm{P}$ treatments resulted in either slight increases $\left(\mathrm{PO}_{4}{ }^{3-}, \mathrm{AEP}, \mathrm{PA}\right)$ or no increase (ATP) in net primary productivity (NPP) (Fig. 5D). Lastly, based on our deviance tests for ecosystem respiration and NPP, we found no evidence for a non-additive effect of the mixture treatment on NPP or R ( $p>0.80)$. 


\section{DISCUSSION}

Resources vary in their nutritional quality, chemical characteristics, and physical accessibility to consumers, which has important implications for a wide range of ecological processes. In the present study, we examined how $\mathrm{P}$ resource heterogeneity influenced the composition and function of aquatic microbial communities. We found that $\mathrm{P}$ resource heterogeneity altered community assembly for bacteria and eukaryotic algae and affected food web and ecosystem attributes such as BP, algal biomass, and ecosystem respiration (R). Together, our results demonstrate that not all $\mathrm{P}$ resources are the same, and that although historically overlooked, $\mathrm{P}$ resource heterogeneity may have important implications for understanding and predicting the structure and function of aquatic communities.

\section{Microbial functional group responses to resource heterogeneity}

P resource heterogeneity was important for some, but not all, microbial functional groups. It is generally assumed that aquatic bacteria and algae respond differently to $\mathrm{P}$ resource supply owing to differences in cell size (Løvdal et al. 2007, Yoshiyama \& Klausmeier 2008), uptake kinetics (Currie \& Kalf 1984, Jansson 1988), and the capacity to use diverse $P$ resources (White \& Metcalf 2007, Bird 2012). For these reasons, we expected that $\mathrm{P}$ resource heterogeneity would have different effects on the composition of bacterial and algal communities, but this was not necessarily the case. In our PERMANOVA models, P heterogeneity explained comparable amounts of variation for bacterial and algal communities (31 and $47 \%$, respectively; Table 4). In addition, BP and algal biomass (chlorophyll a) responded similarly to $\mathrm{P}$ heterogeneity, indicating that shifts in community composition may have translated into functional changes.

The sensitivity of bacterial and algal communities to resource heterogeneity may reflect that these functional groups are specialized in their metabolic capacity to use different forms of P. For example, isolate-based research has demonstrated that aquatic bacteria may specialize on different forms of P (Bird 2012). Furthermore, other studies have shown that resource specialization affects the assembly and diversity of microbial communities (Gómez-Consarnau et al. 2012, Johnson et al. 2012). Our findings lend additional support to the view that bacterial and algal communities may consist of specialist taxa. Specifically, our indicator species analyses revealed that $35 \%$ of bacterial sequences and $87 \%$ of algal sequences belonged to taxa that were associated with a particular P source. Furthermore, these specialized taxa seem to be restricted to only a few bacterial and algal groups. Together, these results suggest that (1) specialization may be important for the assembly of aquatic microbial communities and (2) Pspecialization may occur in some microbial lineages more so than others.

In contrast to bacteria and algae, we observed that the composition of cyanobacteria was insensitive to $\mathrm{P}$ resource heterogeneity (Fig. 4). This finding suggests that, collectively, cyanobacterial communities may consist of resource generalists that share a common repertoire of P-acquisition strategies. A broad phylogenetic distribution of $\mathrm{P}$ genes could arise from horizontal gene transfer, which has been well-documented within cyanobacteria owing to the movement of mobile genomic islands (Coleman et al. 2006), viral transduction (Monier et al. 2012), and the direct uptake of extracellular DNA (Lorenz \& Wackernagel 1994). Alternatively, it is possible that P-acquisition traits were non-randomly distributed among taxa, but that we were unable to detect this signal given the taxonomic resolution of our dataset. For example, functional traits can vary among isolates that are $\sim 99 \%$ similar to one another based on 16S rRNA gene sequences (Hunt et al. 2008). In addition, substantial variation in P-acquisition genes has been documented among marine Prochlorococcus strains isolated from different resource environments (Martiny et al. 2009).

\section{Resource heterogeneity affected microbial functioning}

In addition to influencing microbial community assembly, P resource heterogeneity affected food web attributes and ecosystem processes. Based on decreases in TN and increases in DOC, it appears that $\mathrm{P}$ resource heterogeneity may have consequences for coupled biogeochemical cycles (Burgin et al. 2011). In addition, $P$ resource heterogeneity affected BP, algal biomass (chlorophyll a), and ecosystem respiration (Figs. 2D \& 5A,C). However, other food web and ecosystem variables, such as zooplankton abundance and NPP, were unaffected by resource heterogeneity. The influence of our $\mathrm{P}$ resource manipulations may have been weak for some of the food web and ecosystem attributes 
owing to trophic transfer inefficiency (Borer et al. 2005). In addition, the length of our experiment may have influenced the ability to detect the effects of $\mathrm{P}$ heterogeneity on some response variables. For example, though we observed increases in algal biomass due to P-addition, we did not observe significant changes in total zooplankton abundance. Due to variation in generation times among different taxa, our experiment may not have been long enough to document changes in higher trophic levels (i.e. zooplankton).

\section{Non-additive effects of resource heterogeneity}

When multiple, substitutable resources are found in a system, interactions can arise that have synergistic effects on ecological processes. For example, the consumption of a labile resource may facilitate the uptake of a more recalcitrant resource (e.g. 'priming'; Guenet et al. 2010). Alternatively, the consumption of multiple resources can have antagonistic effects on the performance of an organism (Tilman 1980). We found no evidence to support the hypothesis that there are non-additive effects of multiple $P$ resources on planktonic communities. One interpretation for this result is that the $\mathrm{P}$ resources chosen for this study were ecologically equivalent. However, our community analyses indicate that different microorganisms most likely used P resources in different ways (Fig. 4, Table 4). Furthermore, our results suggest that bacterial communities that assembled under the mixture treatment were a random assortment of the taxa observed under the single resource communities (PERMANOVA, $p=0.47$ ). Overall, there was no evidence for non-additive effects that would arise from antagonistic or facilitatory resource interactions.

\section{The biomolecule model of microbial P-acquisition}

Using model selection techniques, we were able to make inferences about the mechanisms of P heterogeneity that may have influenced aquatic microbial food webs in our study (Tables $3 \& 4$ ). Based on both compositional and functional changes, our findings best support the biomolecule resource substitutability model (Table 2), and suggest that microorganisms may use similar mechanisms to access $P$ resources. In our study, the composition and function of communities receiving biomolecule sources of $\mathrm{P}\left(\mathrm{PO}_{4}{ }^{3-}\right.$ and ATP) were distinct from communities receiving nonbiomolecule sources of P (AEP and PA). These find- ings are consistent with reports of bacterial community responses to $\mathrm{PO}_{4}{ }^{3-}$ and ATP treatments in Lake Mendota (Newton \& McMahon 2011).

We propose that due to cellular demands and chemical properties, microbial communities responded similarly to $\mathrm{PO}_{4}{ }^{3-}$ and ATP treatments. Most microorganisms constitutively express low-affinity $\mathrm{PO}_{4}{ }^{3-}$ transport systems (van Veen 1997). Likewise, ATP belongs to a class of molecules (nucleosides) that microorganisms use independently of P-limitation (Davidson \& Chen 2004). In addition, ATP is a valuable source of energy and nutrition because it contains $\mathrm{C}, \mathrm{N}$, and P. As such, ATP is rapidly consumed by microorganisms in aquatic environments (AlonsoSáez et al. 2012). Therefore, it is likely that microorganisms use ATP as a P source just as easily as $\mathrm{PO}_{4}{ }^{3-}$, which would explain the similarities in community assembly under these 2 resource treatments.

Our biomolecule model of microbial P-acquisition also proposes that structural and storage molecules are processed differently in aquatic food webs. AEP and PA are more resistant to degradation because specialized enzymes are needed to use them as a $\mathrm{P}$ source. For example, enzymes such as hydrolases and lyases are required to cleave the C-P bonds in AEP (Kononova \& Nesmeyanova 2002, VillarrealChiu et al. 2012), and the enzyme phytase is required to release P from PA (Liu et al. 1998, Jorquera et al. 2008). However, not all organisms possess these specialized enzymes. For example, only $28 \%$ of bacterial genomes in the Global Ocean Survey dataset contain genes encoding the ability to cleave C-P bonds (Villarreal-Chiu et al. 2012). Likewise, phytase has only been found in certain microorganisms, mostly taxa belonging to the Gammaproteobacteria (Jorquera et al. 2008). Because not all organisms have the functional capabilities to access $\mathrm{P}$ bound in structural and storage molecules, it is plausible that these P sources influence microbial community assembly by selecting for a subset of specialized taxa.

Our biomolecule model of microbial P-acquisition, however, does not explain the difference observed between microbial communities in low and high $\mathrm{P}$ treatments. If all microorganisms had the capacity to use labile P resources, then we would expect similar microbial communities to assemble in the control, $\mathrm{PO}_{4}{ }^{3-}$, and ATP treatments, but this was not what we observed (Fig. 4). Instead, these particular findings are more consistent with the view that some taxa (i.e. copiotrophs) rapidly respond to nutrient inputs and influence microbial community composition (Koch 2001, Fierer et al. 2007). In addition to explaining compositional differences between low and high $\mathrm{P}$ treat- 
ments, the rapid response of copiotrophic microbes to labile P sources (i.e. $\mathrm{PO}_{4}{ }^{3-}$ and ATP) may contribute to microbial processes observed in our study.

\section{CONCLUSIONS}

P availability plays a critical role in structuring communities and regulating processes in freshwater ecosystems. Comparative approaches have yielded a wealth of predictive models regarding the effects of $P$ on inland water bodies (Peters 1986, Smith 2003). For example, concentrations of TP can sometimes explain large amounts of variation for important trophic state variables such as chlorophyll a (Dillon \& Rigler 1974). However, these statistical models are often derived from logarithmically transformed data (see Kalff 2002) and in many cases there is considerable residual variation that cannot be explained by nutrient concentration alone (Leibold 1999). Aquatic scientists have also used experiments (bottles, mesocosms, and wholelake manipulations) to gain insight into the bottom-up controls of P-limitation on aquatic ecosystems. In almost all cases though, these experiments alter $\mathrm{PO}_{4}{ }^{3-}$ and overlook the fact that aquatic habitats receive and internally generate diverse forms of P (Cade-Menun 2005). In the present study, we provide some of the first lines of evidence that $\mathrm{P}$ resource heterogeneity influences microbial community composition, biogeochemical cycles, and ecosystem processes. However, a number of important issues related to $\mathrm{P}$ heterogeneity must still be addressed. First, as a discipline, we need more studies that quantify the pools and fluxes of different $\mathrm{P}$ compounds in a diverse set of aquatic habitats. Second, to better understand specialist and generalist strategies, we need a more comprehensive description of how $\mathrm{P}$-acquisition genes are distributed among microbial taxa, including heterotrophs and phototrophs, in all 3 domains of life (Bacteria, Archaea, and Eukaryota). Finally, we need to use biogeochemical, microbiological, and molecular techniques to predict the effects of P heterogeneity at the ecosystem scale. Insight from these efforts will improve our understanding of inland water bodies and will potentially help us to better manage aquatic ecosystem services.

Acknowledgements. We thank L. Kinsman-Costello, R. J. Newton, and 3 anonymous reviewers for critical feedback on an earlier version of this manuscript. We acknowledge the National Science Foundation (DEB-0743402 and DEB0842441 to JTL) for financial support. This is Kellogg Biological Station contribution number 1792. All sequence data and metadata have been submitted to NCBI and are avail- able at BioProject PRJNA260460. All code for sequence processing and statistical analyses is available at https://github. com/LennonLab/p-meso.

\section{LITERATURE CITED}

Alonso-Sáez L, Sánchez O, Gasol JM (2012) Bacterial uptake of low molecular weight organics in the subtropical Atlantic: are major phylogenetic groups functionally different? Limnol Oceanogr 57:798-808

Anderson MJ (2001) A new method for non-parametric multivariate analysis of variance. Austral Ecol 26:32-46

Anderson M, Ellingsen KE, McArdle BH (2006) Multivariate dispersion as a measure of beta diversity. Ecol Lett 9: 683-693

Bertz S (1983) On the complexity of graphs and molecules. Bull Math Biol 45:849-855

Bird K (2012) Generalist and specialist strategies of phosphorus acquisition by aquatic bacteria. MS thesis, Michigan State University, East Lansing, MI

Borer ET, Seabloom EW, Shurin JB, Anderson KE and others (2005) What determines the strength of a trophic cascade? Ecology 86:528-537

Briand E, Pringault O, Jacquet S, Torreton JP (2004) The use of oxygen microprobes to measure bacterial respiration for determining bacterioplankton growth efficiency. Limnol Oceanogr Methods 2:406-416

Burgin AJ, Yang WH, Hamilton SK, Silver WL (2011) Beyond carbon and nitrogen: how the microbial energy economy couples elemental cycles in diverse ecosystems. Front Ecol Environ 9:44-52

Burnham KP, Anderson DR (2004) Multimodel inference: understanding AIC and BIC in model selection. Sociol Methods Res 33:261-304

Cade-Menun BJ (2005) Using phosphorus-31 nuclear magnetic resonance spectroscopy to characterize organic phosphorus in environmental samples. In: Turner BL, Frossard E, Baldwin DS (eds) Organic phosphorus in the environment. CABI Publishing, Wallingford, p 21-44

Caporaso JG, Lauber CL, Walters WA, Berg-Lyons D and others (2012) Ultra-high-throughput microbial community analysis on the Illumina HiSeq and MiSeq platforms. ISME J 6:1621-1624

> Carpenter SR, Cole JJ, Hodgson JR, Kitchell JF and others (2001) Trophic cascades, nutrients, and lake productivity: whole-lake experiments. Ecol Monogr 71:163-186

> Cole JR, Wang Q, Cardenas E, Fish J and others (2009) The Ribosomal Database Project: improved alignments and new tools for rRNA analysis. Nucleic Acids Res 37: D141-D145

> Coleman ML, Chisholm SW (2010) Ecosystem-specific selection pressures revealed through comparative population genomics. Proc Natl Acad Sci USA 107:18634-18639

> Coleman ML, Sullivan MB, Martiny AC, Steglich C, Barry K, Delong EF, Chisholm SW (2006) Genomic islands and the ecology and evolution of Prochlorococcus. Science 311: 1768-1770

Currie DJ, Kalf J (1984) A comparison of the abilities of freshwater algae and bacteria to acquire and retain phosphorus. Limnol Oceanogr 29:298-310

> Davidson AL, Chen J (2004) ATP-binding cassette transporters in bacteria. Annu Rev Biochem 73:241-268

Dillon PJ, Rigler FH (1974) The phosphorus-chlorophyll relationship in lakes. Limnol Oceanogr 19:767-773 
Edgar RC, Haas BJ, Clemente JC, Quince C, Knight R (2011) UCHIME improves sensitivity and speed of chimera detection. Bioinformatics 27:2194-2200

Eiler A, Drakare S, Bertilsson S, Pernthaler J and others (2013) Unveiling distribution patterns of freshwater phytoplankton by a next generation sequencing based approach. PLoS ONE 8:e53516

> Elser JJ, Bracken MES, Cleland EE, Gruner DS and others (2007) Global analysis of nitrogen and phosphorus limitation of primary producers in freshwater, marine and terrestrial ecosystems. Ecol Lett 10:1135-1142

Fierer N, Bradford MA, Jackson RB (2007) Toward an ecological classification of soil bacteria. Ecology 88:1354-1364

Finke DL, Snyder WE (2008) Niche partitioning increases resource exploitation by diverse communities. Science 321:1488-1490

Gómez-Consarnau L, Lindh MV, Gasol JM, Pinhassi J (2012) Structuring of bacterioplankton communities by specific dissolved organic carbon compounds. Environ Microbiol 14:2361-2378

Guenet B, Danger M, Abbadie L, Lacroix G (2010) Priming effect: bridging the gap between terrestrial and aquatic ecology. Ecology 91:2850-2861

Heath RT (2005) Microbial turnover of organic phosphorus in aquatic systems. In: Turner BL, Frossard E, Baldwin DS (eds) Organic phosphorus in the environment. CABI Publishing, Wallingford, p 185-203

> Hudson JJ, Taylor WD, Schindler DW (2000) Phosphate concentrations in lakes. Nature 406:54-56

> Hunt DE, David LA, Gevers D, Preheim SP, Alm EJ, Polz MF (2008) Resource partitioning and sympatric differentiation among closely related bacterioplankton. Science 320:1081-1085

> Jansson M (1988) Phosphate uptake and utilization by bacteria and algae. Hydrobiologia 170:177-189

> Johnson DR, Goldschmidt F, Lilja EE, Ackermann M (2012) Metabolic specialization and the assembly of microbial communities. ISME J 6:1985-1991

> Jorquera M, Martínez O, Maruyama F, Marschner P, Mora ML (2008) Current and future biotechnological applications of bacterial phytases and phytase-producing bacteria. Microbes Environ 23:182-191

Kalff J (2002) Limnology: inland water ecosystems. Prentice Hall, Upper Saddle River, NJ

Koch AL (2001) Oligotrophs versus copiotrophs. BioEssays 23:657-661

Kominoski JS, Hoellein TJ, Kelly JJ, Pringle CM (2009) Does mixing litter of different qualities alter stream microbial diversity and functioning on individual litter species? Oikos 118:457-463

> Kononova SV, Nesmeyanova MA (2002) Phosphonates and their degradation by microorganisms. Biochemistry 67 : 184-195

Leibold MA (1999) Biodiversity and nutrient enrichment in pond plankton communities. Evol Ecol Res 1:73-95

> Lennon JT (2007) Diversity and metabolism of marine bacteria cultivated on dissolved DNA. Appl Environ Microbiol 73:2799-2805

> Lennon JT, Smith VH, Dzialowski AR (2003) Invasibility of plankton food webs along a trophic state gradient. Oikos 103:191-203

Liu B, Rafiq A, Tzeng Y, Rob A (1998) The induction and characterization of phytase and beyond. Enzyme Microb Technol 22:415-424

Loreau M (1998) Biodiversity and ecosystem functioning: a mechanistic model. Proc Natl Acad Sci USA 95:5632-5636

Lorenz MG, Wackernagel W (1994) Bacterial gene transfer by natural genetic transformation in the environment. Microbiol Rev 58:563-602

> Løvdal T, Tanaka T, Thingstad TF (2007) Algal-bacterial competition for phosphorus from dissolved DNA, ATP, and orthophosphate in a mesocosm experiment. Limnol Oceanogr 52:1407-1419

> Luo H, Benner R, Long RA, Hu J (2009) Subcellular localization of marine bacterial alkaline phosphatases. Proc Natl Acad Sci USA 106:21219-21223

- Makino K, Shinagawa H, Amemura M, Kawamoto T, Yamada M, Nakata A (1989) Signal transduction in the phosphate regulon of Escherichia coli involves phosphotransfer between PhoR and PhoB proteins. J Mol Biol 210:551-559

> Martiny AC, Tai APK, Veneziano D, Primeau F, Chisholm SW (2009) Taxonomic resolution, ecotypes and the biogeography of Prochlorococcus. Environ Microbiol 11:823-832

> McKane RB, Johnson LC, Shaver GR, Nadelhoffer KJ and others (2002) Resource-based niches provide a basis for plant species diversity and dominance in arctic tundra. Nature 415:68-71

Monier A, Welsh RM, Gentemann C, Weinstock G and others (2012) Phosphate transporters in marine phytoplankton and their viruses: cross-domain commonalities in viralhost gene exchanges. Environ Microbiol 14:162-176

> Needleman SB, Wunsch CD (1970) A general method applicable to the search for similarities in the amino acid sequence of two proteins. J Mol Biol 48:443-453

Newton RJ, McMahon KD (2011) Seasonal differences in bacterial community composition following nutrient additions in a eutrophic lake. Environ Microbiol 13:887-899

- Newton RJ, Griffin LE, Bowles KM, Meile C and others (2010) Genome characteristics of a generalist marine bacterial lineage. ISME J 4:784-798

Odum HT (1956) Primary production in flowing waters. Limnol Oceanogr 1:102-117

Oksanen L, Fretwell SD, Arruda J, Niemela P (1981) Exploitation ecosystems in gradients of primary productivity. Am Nat 118:240-261

Oksanen J, Blanchet FG, Kindt R, Legendre P and others (2013) Vegan: community ecology package. Available at //cran.r-project.org/web/packages/vegan/index.html

Orchard ED, Benitez-Nelson CR, Pellechia PJ, Lomas MW, Dyhrman ST (2010) Polyphosphate in Trichodesmium from the low-phosphorus Sargasso Sea. Limnol Oceanogr 55:2161-2169

Peters RH (1986) The role of prediction in limnology. Limnol Oceanogr 31:1143-1159

Pielou EC (1969) An introduction to mathematical ecology. Wiley, New York, NY

R Core Development Team (2012) R: a language and environment for statistical computing. R Foundation for Statistical Computing, Vienna. Available at www.r-project.org

Schloss PD, Westcott SL, Ryabin T, Hall JR and others (2009) Introducing mothur: open-source, platform-independent, community-supported software for describing and comparing microbial communities. Appl Environ Microbiol 75:7537-7541

> Schoener TW (1974) Resource partitioning in ecological communities. Science 185:27-39

Smith DC, Azam F (1992) A simple, economical method for measuring bacterial protein synthesis rates in seawater using ${ }^{3} \mathrm{H}$-leucine. Mar Microb Food Webs 6:107-114 
Smith VH (2003) Eutrophication of freshwater and coastal marine ecosystems: a global problem. Environ Sci Pollut Res Int 10:126-139

Sommer U, Sommer F (2006) Cladocerans versus copepods: the cause of contrasting top-down controls on freshwater and marine phytoplankton. Oecologia 147:183-194

Sterner RW, Elser JJ (2002) Ecological stoichiometry: the biology of elements from molecules to the biosphere. Princeton University Press, Princeton, NJ

Stomp M, Huisman J, de Jongh F, Veraart AJ and others (2004) Adaptive divergence in pigment composition promotes phytoplankton biodiversity. Nature 432:104-107

Ternan NG, McGrath JW, McMullan G, Quinn JP (1998) Review: Organophosphonates: occurrence, synthesis and biodegradation by microorganisms. World J Microbiol Biotechnol 14:635-647

Tilman D (1980) A graphical-mechanistic approach to competition and predation. Am Nat 116:362-393

Turner BL, Frossard E, Baldwin DS (2005) Organic phosphorus in the environment. CABI Publishing, Wallingford

Tylianakis JM, Rand TA, Kahmen A, Klein AM, Buchmann N, Perner J, Tscharntke T (2008) Resource heterogeneity

Editorial responsibility: Fereidoun Rassoulzadegan, Villefranche-sur-Mer, France moderates the biodiversity-function relationship in real world ecosystems. PLoS Biol 6:e122

van Veen HW (1997) Phosphate transport in prokaryotes: molecules, mediators and mechanisms. Ant Leeuwenhoek 72:299-315

Villarreal-Chiu JF, Quinn JP, McGrath JW (2012) The genes and enzymes of phosphonate metabolism by bacteria, and their distribution in the marine environment. Front Microbiol 3(19):1-13

Wetzel RG, Likens GE (2000) Limnological analyses, 3rd edn. Springer-Verlag, New York, NY

- White AK, Metcalf WW (2007) Microbial metabolism of reduced phosphorus compounds. Annu Rev Microbiol 61:379-400

> Wilson DS, Yoshimura J (1994) On the coexistence of specialists and generalists. Am Nat 144:692-707

> Yilmaz P, Parfrey LW, Yarza P, Gerken J and others (2014) The SILVA and 'All-species Living Tree Project (LTP)' taxonomic frameworks. Nucleic Acids Res 42:D643

> Yoshiyama K, Klausmeier CA (2008) Optimal cell size for resource uptake in fluids: a new facet of resource competition. Am Nat 171:59-70

Submitted: June 30, 2014; Accepted: September 11, 2014 Proofs received from author(s): November 13, 2014 